\title{
Optimizing the Bituminous Concrete Mixes for Fatigue Performance
}

\author{
K. Kantha Kumar*,1 and A.Veeraragavan ${ }^{2}$
}

\author{
${ }^{I}$ Research Scholar, Transportation Engineering Division, Department of Civil Engineering, Indian Institute of Technol- \\ ogy Madras, India; ${ }^{2}$ Professor, Transportation Engineering Division, Department of Civil Engineering, Indian Institute \\ of Technology Madras, India
}

\begin{abstract}
The objective of the present research work is to study the influence of aggregate gradation on fatigue performance and of Bituminous Concrete (BC) mixes, and to optimize the bituminous concrete mix for fatigue performance of within the specification band which offers longer fatigue life. Five aggregate gradations for an bituminous concrete mix falling within the specification band limit for bituminous surface course are considered. Repeated load indirect tensile fatigue test is carried out at 30,35 and $40{ }^{\circ} \mathrm{C}$ using gyratory compacted cylindrical specimens. Laboratory fatigue test results are used for developing the optimization model considering stiffness modulus, horizontal tensile strain and air void as the constraints. Sensitivity analysis is also carried out to study the effect of variation in constraints values on fatigue life.
\end{abstract}

\section{INTRODUCTION}

Bituminous Concrete (BC) mix is a combination of aggregate and bitumen binder. The aggregate acts as the structural skeleton of the pavement and the bitumen binder as the glue of the mixture. As a construction material asphalt concrete is much more complicated than it appears. It is a composite material consisting of aggregate particles (hard pieces of rock) of different sizes; a bitumen binder that is much softer than the aggregate, and air voids Roberts et al. (1996) [1]. The response of this mix to traffic and environmental loads depends on the properties of the constituents and the proportion (by volume) of each. In turn, the performance of the $\mathrm{BC}$ mix in rutting, cracking, and durability is directly related to the mixture response to loads Deacon et al. (1994) [2]. The mineral aggregate matrix, including coarse and fine particles in asphalt concrete paving mixtures, encompasses approximately 90 to 95 percent of mix volume. The properties of the aggregate have direct and significant effect on the performance of bituminous concrete pavements. Research work has been dedicated to characterizing the physical properties of aggregate (strength, shape, texture) and their relationship to the behavior of asphalt concrete mix for pavement construction Sousa et al. (1998) [3].

Highway engineers often refer to an aggregate skeleton in the mixture when discussing the role of aggregate. Indeed, most of the compressive strength and resistance to movement under truck loads are offered by the aggregate. Properties of the skeleton are related directly to the hardness, shape, texture, and gradation of the aggregates. Of these properties, gradation is the most unstructured.

Theoretically, it would seem reasonable that the best gradation for asphalt concrete mix is the one that results in the densest particle packing. The gradation resulting maximum theoretical density provides increased stability through increased interparticle contacts and reduced voids in the

*Address correspondence to this author at the Research Scholar, Transportation Engineering Division, Department of Civil Engineering, Indian Institute of Technology Madras, India; Tel +919444896903;

E-mail:kantha@iitm.ac.in mineral aggregate Huang et al. (1970) [4]. However, sufficient air void space is required to permit enough binder cement to be incorporated to ensure durability, while still leaving some air space in the mixture to avoid bleeding. A tightly packed aggregates (low voids in mineral aggregate) also results in a mixture that is more sensitive to slight changes in asphalt content.

The performance of bituminous concrete mix is related to particle size distribution, which affects the most important properties of the mix, such as cracking resistance, rutting resistance, durability, permeability, and workability. Therefore, having a proper aggregate particle distribution is a very important factor for satisfactory field performance Roque $e t$ al. (2006) [5]. Typically the selection of aggregate gradation is based on specification bands within control points, but the main question is how to choose the best possible blend within the specified band to achieve better performance?

The specific objective of this research work is to study the effect of aggregate gradation on fatigue performance of bituminous concrete mixes and to select the optimum aggregate gradation within the specification band limit which offers better fatigue performance. The selected gradations for surface course bituminous concrete mix, fall within the specification band limit of the Ministry of Road Transport and Highways, Government of India MoRTH (2001) [6].

\section{MATERIALS, TEST METHODS AND RESULTS}

\section{Bitumen Binder}

Bitumen of $60 / 70$ penetration grade is used for this investigation.

\section{Aggregates}

Crushed granite of coarse and fine aggregates is obtained by crushing of aggregates obtained from a quarry near Chennai, Tamil Nadu, India. The crushed stone is sieved into various fractions after washing and drying. Ordinary Portland cement is used as filler material. The properties of the selected aggregates are within the requirements as specified by the Ministry of Road Transport and Highways (MORTH 2001). 
Table 1. Physical Properties of Binder

\begin{tabular}{|c|c|c|}
\hline Physical Property & Test Method & Binder Grade 60/70 \\
\hline \hline Penetration at $25^{\circ} \mathrm{C}(100 \mathrm{~g}, 5 \mathrm{~s}), 1 / 10^{\text {th }}$ of $\mathrm{mm}$. & ASTM D5-05a & 66 \\
\hline Softening point(Ring and Ball $),{ }^{0} \mathrm{C}$, minimum & ASTM D 36 & 74 \\
\hline Ductility at $27^{\circ} \mathrm{C}(5 \mathrm{~cm} /$ min pull $)$, minimum & ASTM D 113-99 & 1.01 \\
\hline Specific gravity & ASTM D 70 & \\
\hline
\end{tabular}

Table 2. Properties of Aggregate Tested

\begin{tabular}{|c|c|c|}
\hline Properties Tested & Test Results & MoRTH Specification \\
\hline \hline Crushing Value & $33 \%$ & $45 \% \mathrm{Max}$ \\
\hline Aggregate Impact Value & $28 \%$ & $30 \% \mathrm{Max}$ \\
\hline LosAngeles Abrasion Value & $14 \%$ & $30 \%$ Max \\
\hline Water Absorption Value & $0.85 \%$ & $2 \% \mathrm{Max}$ \\
\hline Specific Gravity & $2.65 \%$ & $2.5-3.0$ \\
\hline Combined (EI + FI) Index & $20 \%$ & $30 \% \mathrm{Max}$ \\
\hline
\end{tabular}

\section{Aggregate Gradation}

Five aggregate gradations for a Bituminous Concrete (BC) mix falling within the specification band limit for application of surface course are considered. The gradations and mix designations considered in the present study are presented in Table 1. The gradation curve is shown in Fig. (1).

LL-Lower limit (Lowest gradation line (coarse graded)), OF-One fourth (between LL and MP (coarse graded)), MP-
Mid point (Middle most gradation line), TF-Three fourth (between MP and UL (fine graded)), UL-Upper limit (upper most gradation line above TF).

\section{Specimen Preparation}

Bituminous Concrete (BC) mix specimens are prepared at optimum binder content, by mixing the aggregates and binder at desired mixing temperatures, and compacted using gyratory compactor for high traffic level $\left(\mathrm{N}_{\mathrm{ini}}=9, \mathrm{~N}_{\mathrm{des}}=125\right.$, and $\mathrm{N}_{\max }=205$ AASHTO TP4, (1999) [7] at desired compact-

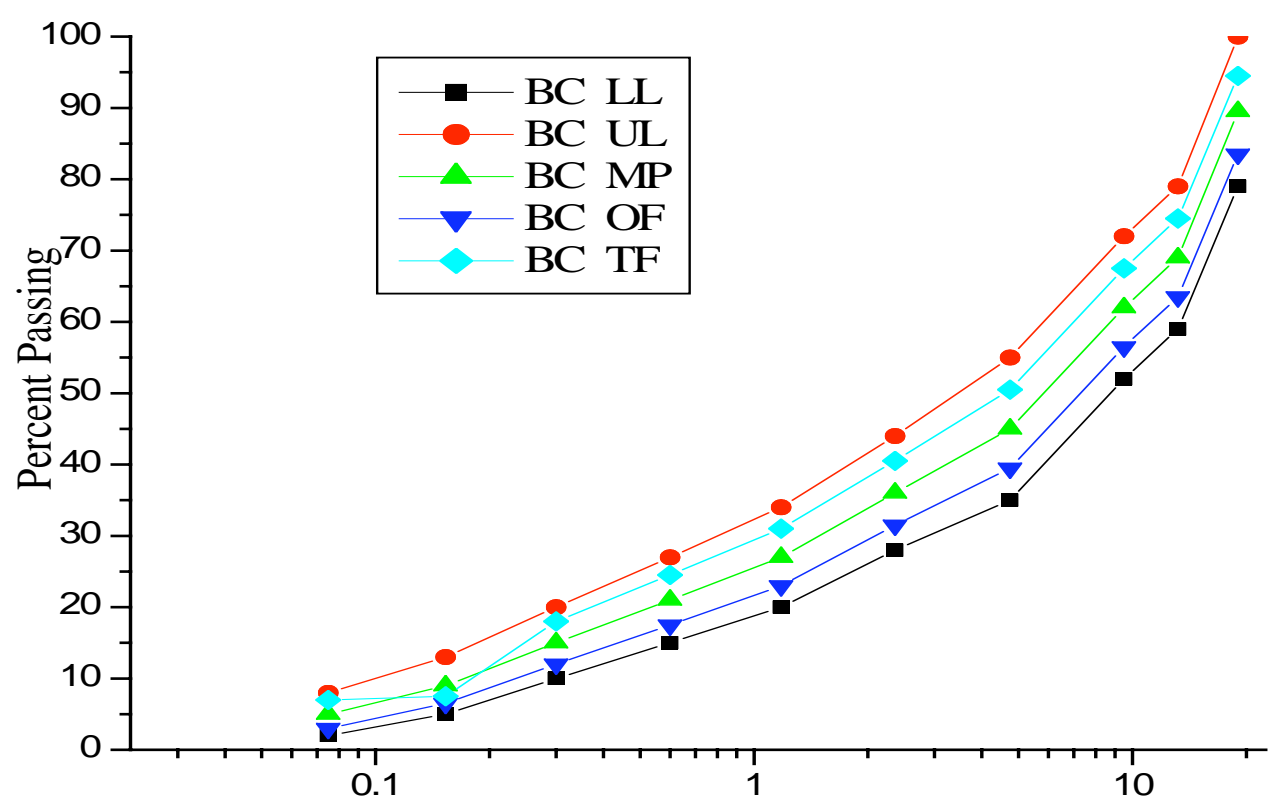

Sieve Size, $\mathrm{mm}$

Fig. (1). Aggregate Gradation used in the Study (0.45 power curve). 
Table 3. Aggregate Gradation Considered in the Present Investigation

\begin{tabular}{|c|c|c|c|c|c|c|}
\hline \multicolumn{7}{|c|}{ BITUMINOUS CONCRETE (BC) GRADE - I } \\
\hline Sieve Size, mm & \multicolumn{6}{|c|}{ Cumulative \% by weight of Total Aggregate Passing } \\
\hline 26.5 & 100 & 100 & 100 & 100 & 100 & 100 \\
\hline 19 & $79-100$ & 79 & 83.5 & 89.5 & 94.5 & 100 \\
\hline 9.5 & $52-72$ & 52 & 56.5 & 62 & 67.5 & 72 \\
\hline 4.75 & $35-55$ & 35 & 39.5 & 45 & 50.5 & 55 \\
\hline 2.36 & $28-44$ & 28 & 31.5 & 36 & 40.5 & 44 \\
\hline 0.15 & $5-13$ & 5 & 6.5 & 9 & 7.5 & 13 \\
\hline 0.075 & $2-8$ & 2 & 3 & 5 & 7 & 8 \\
\hline
\end{tabular}

ing temperatures. The specimen after conditioning for two hours at desired temperature is placed between two steel strips so that the central axes of the strips, specimen and piston are in the same vertical plane. A constant repeated load is applied at a loading frequency of 5 hertz with a desired loading period of 0.2 second and rest period of 0.8 second. Haversine type of loading waveform is used, as this is the closest waveform that experienced in the field, since the loading pulse is followed by a rest period. The load repetitions are continued till the specimen failed. When the permanent horizontal deformation in the specimen is $5 \mathrm{~mm}$, the tensile crack is about $0.8 \mathrm{~mm}$ wide and is found to be adequate to describe the fatigue life for a given mix Gilmore et al. (2007) [8]. Fatigue life of the $\mathrm{BC}$ mix is the number of load repetitions to cause failure of the specimen as above. The specimens are tested at two test temperatures viz., 30, 35 and 40 ${ }^{\circ} \mathrm{C}$.

\section{Volumetric Analysis}

Volumetric analysis is carried out as per AASHTO: T 166 [9] and the results are tabulated in Table 2. It can be observed that the bulk specific gravity and the Voids in Min- eral Aggregate (VMA) of the BC mix increases with increase in finer particles, while the air voids decreases.

\section{Repeated Load Indirect Tensile Fatigue Test}

The pavement materials are subjected to cyclic stresses due to repeated application of loads by fast moving vehicles. In view of this, it is decided to carry out repeated load indirect tensile test to determine fatigue life and other resilient characteristics of paving mixes. This test is similar to static indirect tensile test, but in this case, repeated loads are applied and resulting horizontal and vertical deformation measurements are made. Literature review is carried out to identify the available methods of fatigue testing. It is concluded that a study should be conducted using indirect tensile mode of testing as it presented a simple and inexpensive test method utilizing cylindrical specimens that could also be cored from a pavement if needed. The specimens are subjected to repeated diametric line loading along the vertical diameter which generates an indirect tensile stress on the horizontal diameter. This vertical loading produces both vertical compressive stress and horizontal tensile stress on the diameters of the specimen. The magnitudes of the stresses

Table 4. Results of Volumetric Analysis and Resilient Modulus

\begin{tabular}{|c|c|c|c|c|}
\hline Mix Type & Bulk Specific Gravity & Air Voids, \% & Voids in Mineral Aggregate, \% & Resilient Modulus $\left(\mathbf{M}_{\mathbf{R}}\right)$, MPa \\
\hline \hline BC-LL & 2.382 & 4.5 & 15.2 & 1989 \\
\hline BC-OF & 2.388 & 4.2 & 15.5 & 2266 \\
\hline BC-MP & 2.387 & 4 & 16.4 & 2410 \\
\hline BC-TF & 2.39 & 3.8 & 16.8 & 2600 \\
\hline BC-UL & 2.393 & 3.6 & & 2505 \\
\hline
\end{tabular}


vary along the diameters, but are maximum at the center of the specimen Deacon et al. (1967) [10].

It can be observed from Table 3 that the laboratory fatigue life for asphalt concrete mix is found to be optimum for BC-TF mix at all the temperature and stress level.

\section{Optimizing the Bituminous Concrete mix for Fatigue Performance}

The main objective of this research work is to optimize the bituminous concrete mixes for fatigue performance. In order to do this, BC-Grade I as specified in the Ministry of Road Transport and Highways (MORTH), is selected. Five aggregate gradations for a BC mix falling within the specification band limit for application of surface course are considered. The volumetric analysis and the indirect tensile fatigue test results of all the five mixes studied are used for developing optimization model.

\section{Formulating the Objective Function and Constraints}

Objective is to maximize the fatigue life, subjected to the constraints of air voids, stiffness modulus and horizontal tensile strain.

Micromath scientific software [11] is used for developing the objective function equation.

Objective function is obtained by inputting the dependent (Fatigue life) and the independent variables (air voids, stiffness modulus, and horizontal tensile strain). Following is the objective function equation.

Maximize $\mathrm{Y}=1.8+(2.9 * \mathrm{x} 1)+\left(4.56^{*} \mathrm{x} 2\right)+(2.5 * \mathrm{x} 3)$ eqn $\ldots 1$

Subjected to constraints at bounds;

3.6, x1, 4.5;
$1989, x 2,2600$;

$75, \mathrm{x} 3,125$;

Where

$\mathrm{Y}=$ Fatigue life,

$\mathrm{x} 1=$ Air Voids $(\%)$,

$\mathrm{x} 1=$ Stiffness modulus $(\mathrm{MPa})$

x1=Horizontal Tensile Strain (Microstrain).

The optimization solution is obtained by inputting the above objective function equation and the constraints in the LINGO software [12], which solves the optimization problem by simplex method. Following is the output from the software.

Global optimization solution found at iteration: 8

Objective value: 9625

Variable Value

$\mathrm{X} 1 \quad 3.9$

$\mathrm{X} 1$

$\mathrm{X} 1$

The above results are compared with the Table $\mathbf{4}$ and $\mathbf{5}$, it can be observed that at $30{ }^{\circ} \mathrm{C}$ and 20 per cent stress level the BC-TF very closely matches with the output obtained.

\section{Sensitivity Analysis}

Sensitivity analysis is the study of how model output varies with changes in model inputs. A model is said to be sensitive to an input if changing that input variable changes the model output. This output variability can be apportioned,

Table 5. Indirect Tensile Fatigue Test Results

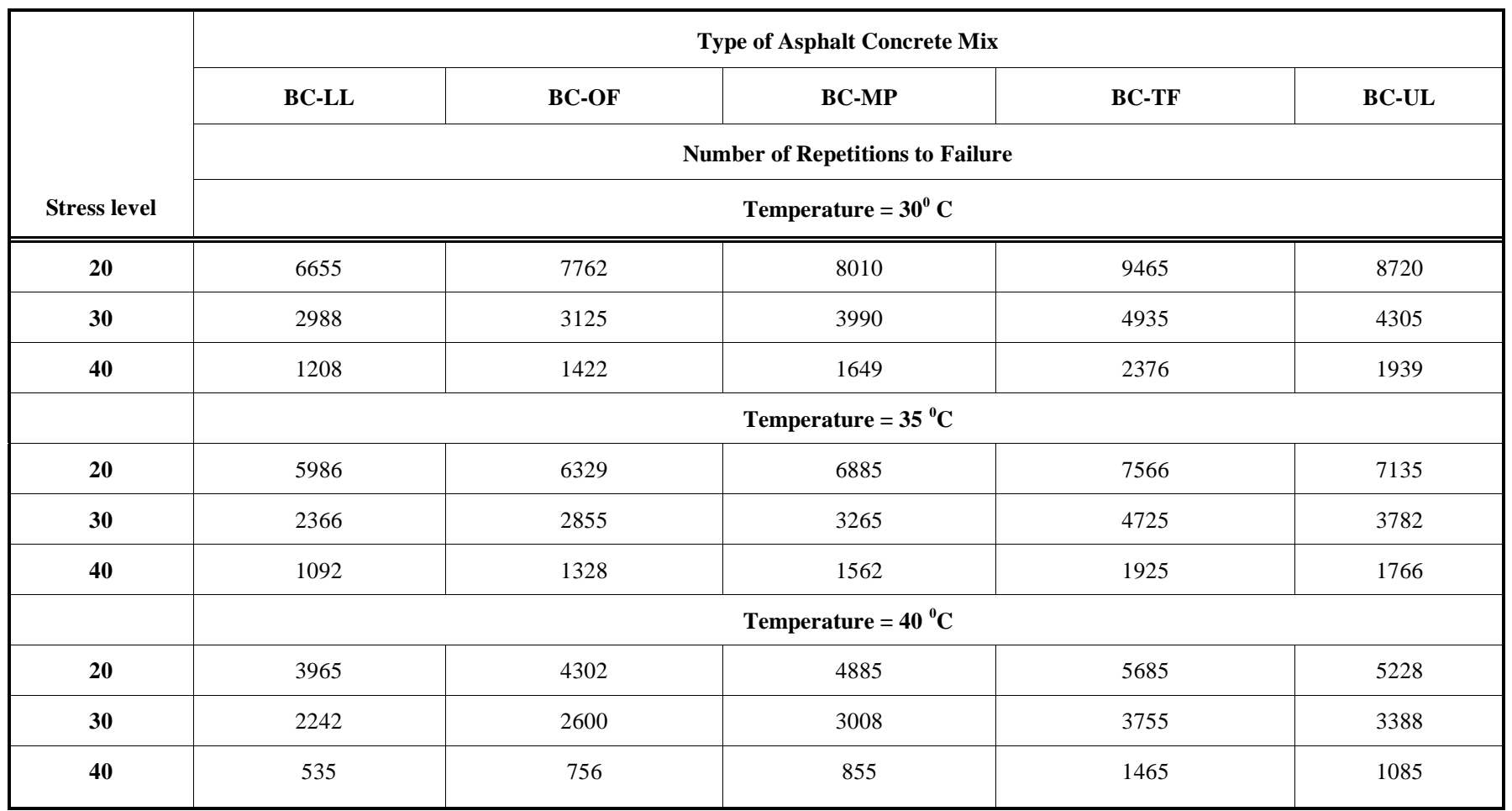


Table 6. Input Variables for Sensitivity Analysis

\begin{tabular}{|c|c|c|c|}
\hline Fatigue Life & Air Voids & Stiffness & Horizontal Tensile Strain \\
\hline \hline 6655 & 3.6 & 1989 & 75 \\
\hline 7762 & 3.8 & 2266 & 82 \\
\hline 8010 & 4 & 2410 & 95 \\
\hline 9465 & 4.2 & 2600 & 113 \\
\hline 8720 & 4.5 & 2505 & 125 \\
\hline
\end{tabular}

qualitatively or quantitatively, to different sources of variation in the inputs Cacuci et al. (2003) [13].

\section{Methodology}

There are several possible procedures to perform sensitivity analysis (SA). The most common sensitivity analysis is sampling-based. A sampling-based sensitivity is one in which the model is executed repeatedly for combinations of values sampled from the distribution (assumed known) of the input factors. Other methods are based on the decomposition of the variance of the model output and are model independent Saltelli et al. (2004) [14].

\section{Table 7. Results of Sensitivity Analysis}

\begin{tabular}{|c|c|c|}
\hline 9270 & 9270 & 9270 \\
\hline 10550 & 9288 & 10533 \\
\hline 11239 & 9321 & 11191 \\
\hline 12151 & 9366 & 12057 \\
\hline 11748 & 9397 & 11625 \\
\hline 9270 & 10533 & 9287 \\
\hline 10551 & 10551 & 10551 \\
\hline 11240 & 10584 & 11208 \\
\hline 12151 & 10629 & 12075 \\
\hline 11748 & 10660 & 11643 \\
\hline 9271 & 11189 & 9320 \\
\hline 10551 & 11207 & 10583 \\
\hline 11241 & 11241 & 11241 \\
\hline 12152 & 11286 & 12107 \\
\hline 11749 & 11317 & 11675 \\
\hline 9271 & 12056 & 9365 \\
\hline 10552 & 12074 & 10628 \\
\hline 11241 & 12107 & 11286 \\
\hline 12152 & 12152 & 12152 \\
\hline 11749 & 12183 & 11720 \\
\hline 9272 & 11623 & 9395 \\
\hline 10553 & 11641 & 10658 \\
\hline 11242 & 11674 & 11316 \\
\hline 12153 & 11719 & 12182 \\
\hline 11750 & 11750 & 11750 \\
\hline
\end{tabular}

The model is evaluated and the computed distribution of the target function (Objective function) is shown in Table 7. It can be observed that the variation in the output of the sensitivity analysis is less than eighteen per cent compared to optimal value.

\section{CONCLUSIONS}

This paper presented an evaluation of fatigue performance and optimizing the bituminous concrete mixes with different aggregate gradations based on the ones proposed by the Ministry of Road Transport and Highways for surface courses. Based on results the following conclusions are drawn.

- Optimum aggregate gradation is found to be BC-TF which gives maximum fatigue life.

- $\quad$ The optimization model developed closely predicts the optimum fatigue life with less than five per cent variation.

- The result of the sensitivity analysis shows that the model output is having variation of less than eighteen per cent with changes in model inputs.

\section{REFERENCES}

[1] F.L. Roberts, P.S. Kandhal and E.R. Brown. Hot Mix Asphalt Design and Construction, Second Edition. NAPA Education Foundation, Lanham, Maryland. p. 156, 1996.

[2] J.A.Deacon, J. Tayebali, F. Finn. Coplantz, and C.L. Monismith.1994. Fatigue Response of Asphalt -Aggregate Mixes, Strategic Highway Research Program Report No. SHRP-A- 404, PartIII Mix Design and Analysis, National Research Council, Washington, D.C.

[3] Sousa, B. Jorge, Pais, C. Jorge, Prates, Manuel et al. 1998. Effect of Aggregate Gradation on Fatigue Life of Asphalt Concrete Mixes, Transportation Research Record, Journal of Transportation Research Board, n 1630, Washington, D.C. Sep. p 62-68.

[4] E.Y. Huang. A Study of Strength Characteristics of AsphaltAggregate Mixtures as Affected by the Geometric Characteristics and Gradation of Aggregate, Journal of the Association of Asphalt Paving Technologists, Vol. 39, p. 98-133, 1970.

[5] R.Roque, B. Birgisson and S. Kim. Development of Mix Design Guidelines for Improved Performance of Asphalt Mixtures, Final Report Submitted to Department of Civil and Coastal Engineering, College of Engineering, University of Florida. p. 1-16, 2006.

[6] Ministry of Road Transport and Highways (MoRT\&H). 2001 Specification for Roads and Bridge Works, Government of India, Indian Roads Congress, New Delhi, India, $4^{\text {th }}$ Revision.

[7] Method for Preparing and Determining the Density of HMA Specimens by Means of the SHRP Gyratory Compactor, AASHTO TP 4, 1999.

[8] Gilmore, D.W., R.P. Lottman, J.A. Scherocman. Use of Indirect Tension Measurements to Examine the Effect of Additives on As- 
phalt Concrete Durability. Journal of the Association of Asphalt Paving Technologists, Vol. 53, p. 495, 2007.

[9] Standard Test Method for Bulk Specific Gravity of Compacted Bituminous Mixtures Using Saturated Surface-Dry Specimens, AASHTO T 166.

[10] J.A. Deacon and C.L. Monismith. Fatigue of Asphalt Paving Mixtures, Highway Research Record (HRR), Highway Research Board (HRB), National Research Council, Washington, D.C, No 158, 1967.
[11] Micromath software www.micromath.com 14/11/07

[12] Lingo, Gloabal Optimization Solution. http://www.lindo.com/ products/lingo/lingom.html 14/11/07

[13] Cacuci, Dan G. In Sensitivity \& Uncertainty Analysis, Volume 1: Theory; Chapman \& Hall, 2003.

[14] A. Saltelli, S. Tarantola, F. Campolongo and M. Ratto. 2004, Sensitivity Analysis in Practice. A Guide to Assessing Scientific Models, John Wiley \& Sons publishers. 